\title{
Analysis of the power extraction rate change for boreholes in time and in different heat load conditions
}

\author{
Natalia Fidorów-Kaprawy ${ }^{1, *}$, and Ewelina Stefanowicz ${ }^{1}$ \\ ${ }^{1}$ Wroclaw University of Science and Technology, Faculty of Environmental Engineering, \\ Wybrzeże Wyspiańskiego 27, 50-370 Wrocław, Poland
}

\begin{abstract}
Paper shows the performance analysis of the boreholes being the lower heat source for the brine-to-water heat pump. Researchers focused on the changes of the specific power extraction rate change in time and in various loads. The measurements were the continuation of the analysis of the differences between the Thermal Response Test (TRT) and exploitation data made in 2016/2017 heating season. The heat source performance under greater load and in longer period have been examined. The analysis showed brine temperature drop in overload work conditions even when ambient temperature was high and severe heat source destabilization despite a return to original performance.
\end{abstract}

\section{Introduction}

Interest in ground source heat pumps (GSHP) has recently increased in Poland and in the world. This systems use shallow geothermal energy to provide heating and cooling for buildings. As a heat source with a very high efficiency, they allow to reduce the pollutant emission caused by conventional sources, being a very good alternative for buildings heating. Heat pumps are a low-temperature energy sources. Energy stored in the ground is transferred and adapted to the needs of heating and hot tap water installations. To ensure stable operation of the installation and its failure-free operation, careful design is necessary. There are several reasons for the potential freezing of the ground around the heat exchanger. These are mainly incorrect calculation of the power and energy demand of the building, incorrect assumption of thermal properties of the ground (i.e. thermal conductivity), higher power specific extraction rate than assumed in the project [1]. The effect of overcooling or freezing the soil around Borehole Heat Exchanger (BHE) has a direct impact on the heat carrier fluid average temperature and on the heat pump's efficiency [2]. In practice, the BHE length is dictated by the thermal conductivity and diffusivity of the soil, which can be determined by the Thermal Response Test (TRT) [3]. Depending on the size of the installation, the required accuracy of determining the soil parameters is different. For small installations (up to 10 BHE's), the choice of the ground

\footnotetext{
* Corresponding author: natalia.fidorow@pwr.edu.pl
} 
heat exchanger size is mainly based on the assumptions of power specific extraction rate. A pilot drilling and geological analysis are not often carried out due to high costs. For larger installations (over 10 BHE's), a pilot drilling and a TRT are performed to accurately determine the soil parameters. These are effective methods, however, the problem is the analysis of test data, especially in engineering practice. Simple linear models do not take into account the ground water flow and disturbances during the test [4]. Numerical models are too complicated to find practical applications [5]. In principle, the design of the lower heat source is the most correct when the power extraction is low. The low power specific extraction rate ensures high average brine temperature and high efficiency. As a result, the heat pump's coefficient of performance is maintained regardless of the ambient temperature and heating load. Designing ground heat exchangers with low power specific extraction rate, however, leads to a significant increase in the size of the exchanger, and thus to an increase in investment and operating costs associated with pumping of heat carrier fluid. All the time, methods for determining the limit of power extraction rate for the ground conditions are sought. This capacity limit should be understood as one that does not lead to excessive cooling of the ground around the exchanger. Researchers note how the sustainable exploitation of a ground heat exchanger can affect the long work of GSHP and avoid long-term loss of underground heat storage [6].

In a previous publication, the differences between the results of a typical TRT test and the results of short-term exploitation under the conditions of two loads: according to TRT and lower were discussed [7]. The results of this test indicated a very large dependence between the size of the ground heat exchanger and stability of operation, as well as the consequences resulting from improper design of the GSHP system. This article describes the further part of the research aiming for checking how increased heat load will affect the long-term system operation.

\section{Installation and measuring devices}

The system on which this and previous study and analysis have been performed acts as the heat source for the CTE (Energy Technology Centre) office building in Świdnica since 2012. The underfloor heating system works for the $533 \mathrm{~m}^{2}$ building ground floor area and is designed to deliver around 24.6 MWh of energy during the heating season. The energy is delivered by the BW 117 type brine-to-water heat pump with the nominal thermal power of $17.6 \mathrm{~kW}$, the cooling capacity of $13.8 \mathrm{~kW}$ and the COP of 4.4 (B0/W35). The low heat source consists of five boreholes (the single U-pipe (PE 40x4.0 mm) surrounded by bentonite filler), each $78 \mathrm{~m}$ deep, $6 \mathrm{~m}$ apart. The heat transferring agent is the propylene glycol solution in water $\left(1032 \mathrm{~kg} / \mathrm{m}^{3}, 3900 \mathrm{~kJ} /(\mathrm{kg} \cdot \mathrm{K})\right.$, concentration $\left.34 \%\right)$. Three boreholes are equipped in measuring devices. There are Pt 1000 type, class B (permissible deviation $\pm 0.3 \mathrm{~K}$, standard deviation for a $\mathrm{B}$ type measurement is $0.17 \mathrm{~K}$ ) temperature sensors located every 5 meters about $10 \mathrm{~cm}$ from the polyethylene pipe in the bentonite (16 pieces in each borehole). In the boreholes' measurement wells there are the Endress\&Hausner Proline PROMAG electromagnetic flow meters (1\% accuracy) and Endress\&Hausner Omnigrad M TST90 coupled temperature sensors (accuracy of a temperature difference measurement of $\pm 0.05 \mathrm{~K}$ and an individual sensor accuracy of $\left.\pm(0.15+0.002 \cdot|t|)^{\circ} \mathrm{C}\right)$. The summary volumetric flow in the system is around $2.8 \mathrm{~m}^{3} / \mathrm{h}$ (the minimum flow rate for the heat pump is $2541.4 \mathrm{l} / \mathrm{h}$ ). The assumed flow rate for each borehole in case of 5 boreholes performance is around $0.55 \mathrm{~m}^{3} / \mathrm{h}$ (the real operational data are $0.51 \mathrm{~m}^{3} / \mathrm{h}$ for the tested boreholes number 1 and 3 ). In case of 3 boreholes performance (for the purpose of the research) the flows are: in the borehole number $1-0.96 \mathrm{~m}^{3} / \mathrm{h}$ and for the borehole number $3-0.94 \mathrm{~m}^{3} / \mathrm{h}$. 


\section{The heat pumps' lower heat source performance}

The experiment started when TRT test have been performed for two boreholes (1 and 3) in October 2015. The outcomes encouraged the researchers to perform some tests on the system. Two out of five boreholes have been cut off for two weeks in February 2017. Exploitation data have been compared to the period with similar weather at the turn of December 2014 and January 2015. That experiment had been described in the article [7]. Authors concluded that the lower heat source load increase resulted in severe brine temperature drop and that the ground water flow was the important factor that influenced the TRT results. Those results inspired the researchers to perform more tests. Current study concerns the longer performance test with three boreholes. It has been made to evaluate the lower heat source performance and as a part of study aiming for development of the method for more accurate determination of ground thermal properties.

The heating season started on $25^{\text {th }}$ September 2017. The heat pump worked with three boreholes till $12^{\text {th }}$ December 2017, when the flow temperature of the brine dropped to $4^{\circ} \mathrm{C}$, which would run the risk of negative brine temperature occurrence on the heat pump return and possible boreholes freezing. Then the heat pump have been switched for five boreholes and worked this way till $10^{\text {th }}$ of April 2018, which was the end of heating season.

In figures 1, 2 and 3 the system performance in subsequent labour cycles have been presented. Researchers decided to show the heat pump stable performance (January 2015), long term performance with three boreholes (one month in October and November 2017) and the heat pump performance after boreholes have been overloaded (six weeks from January to March 2018). The heat pump labour cycle is the period from the compressor start to its shutoff. The calculations were performed in one-minute step and averaged in labour cycles. The ambient temperature $\left(T_{a}\right)$, the brine temperature outlet $\left(T_{\text {brine, } 1}\right.$ and $\left.\mathrm{T}_{\text {brine,3}}\right)$ were showed. The average power specific extraction rate $\left(\mathrm{q}_{(\mathrm{B} 1) \text { avg }}\right.$ and $\left.\mathrm{q}_{(\mathrm{B} 3) \text { avg }}\right)$ of the boreholes number 1 and 3 have been calculated basing on the flow, inlet and outlet temperatures measurements and the BHE length. The maximum power specific extraction rate $\left(\mathrm{q}_{(\mathrm{B} 1) \max }\right.$ and $\left.\mathrm{q}_{(\mathrm{B} 3) \max }\right)$ have been also determined for each labour cycle.

\subsection{Operation with five boreholes in 2015}

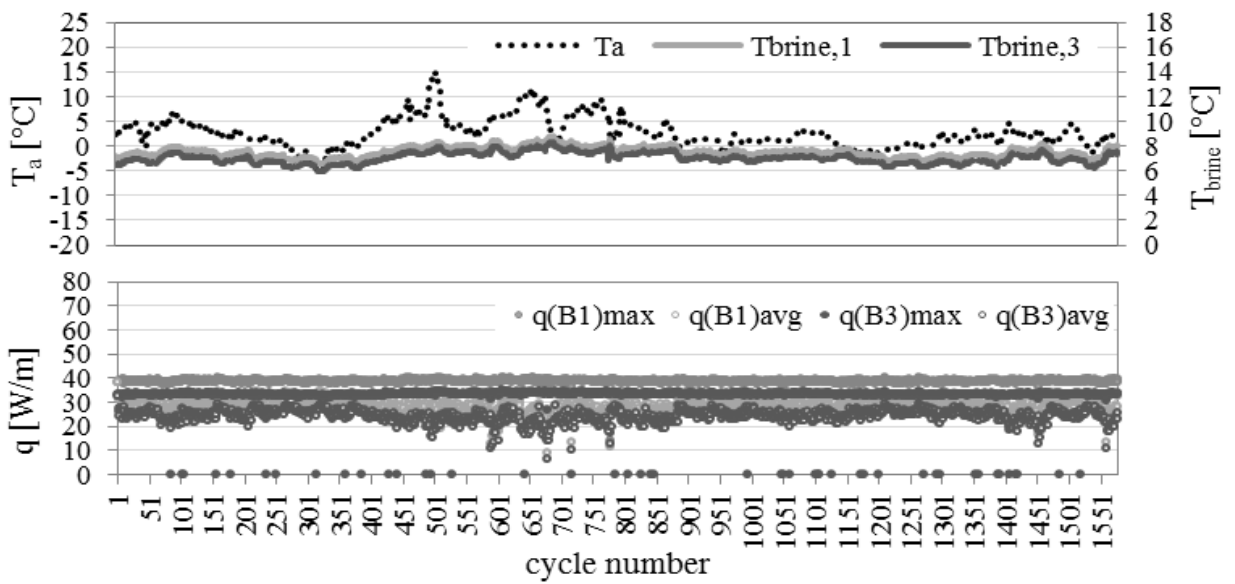

Fig. 1. The exploitation of the heat pump's energy source with five boreholes (one month of the operation in January 2015). 
The stable performance of the brine-to-water heat pump's lower heat source is presented in the Figure 1. The heat pump worked with five boreholes from the beginning of heating season. The ambient air temperature $\left(\mathrm{T}_{\mathrm{a}}\right)$ during the month presented in the Figure 1 (January 2015) ranged between $-5^{\circ} \mathrm{C}$ and $+15^{\circ} \mathrm{C}$. The Borehole 1 maximum power specific extraction rate was around $\mathrm{q}_{(\mathrm{B} 1) \max }=39 \mathrm{~W} / \mathrm{m}$ and Borehole 3 - around $\mathrm{q}_{(\mathrm{B} 3)_{\max }}=33 \mathrm{~W} / \mathrm{m}$. The average power extraction rate for boreholes also differed one from another and were around $4-5 \mathrm{~W} / \mathrm{m}$ greater for Borehole 1. For lower ambient air temperatures, the average power extraction rates of boreholes have been getting close to the maximum values. Despite the greater load of the Borehole 1, the brine temperature on this borehole outlet $\left(\mathrm{T}_{\text {brine, } 1}=7.7^{\circ} \mathrm{C}\right)$ was higher than for the Borehole $3\left(\mathrm{~T}_{\text {brine, } 3}=7.1^{\circ} \mathrm{C}\right)$. The flow temperature of the brine is stable in both boreholes (during examined period it changes no more than by $2.5 \mathrm{~K})$.

\subsection{Operation with three boreholes in 2017}

The performance of the brine-to-water heat pump's lower heat source (operation with three boreholes) is presented in the Figure 2. The heat pump worked with three boreholes from the beginning of heating season. The ambient air temperature $\left(\mathrm{T}_{\mathrm{a}}\right)$ during one month presented in the Figure 2 (last week of October and three weeks of November 2017) ranged between $0^{\circ} \mathrm{C}$ and $17^{\circ} \mathrm{C}$. The Borehole 1 maximum power specific extraction rate was around $\mathrm{q}_{(\mathrm{B} 1) \max }=64 \mathrm{~W} / \mathrm{m}$ and Borehole $3-$ around $\mathrm{q}_{(\mathrm{B} 3) \max }=54 \mathrm{~W} / \mathrm{m}$. The average power extraction rate for boreholes also differed one from another and were around 9-10 W/m higher for Borehole 1. It can be seen that when the ambient air temperature was lower, the average power extraction rates of boreholes also had been getting close to the maximum values. Because of the relatively high ambient temperatures this phenomena is not as vivid as in Figure 1. It is also visible that despite relatively low building heat demand (high external temperatures) the maintenance of the long-term power extraction rate on the level of $60-70 \mathrm{~W} / \mathrm{m}$ is impossible. The decrease in heat extraction rate is due to the ground temperature drop caused by BHE overload. Such operation results in the successive brine temperature decrease (during this warm month the differences reached around $5.0 \mathrm{~K}$ ).

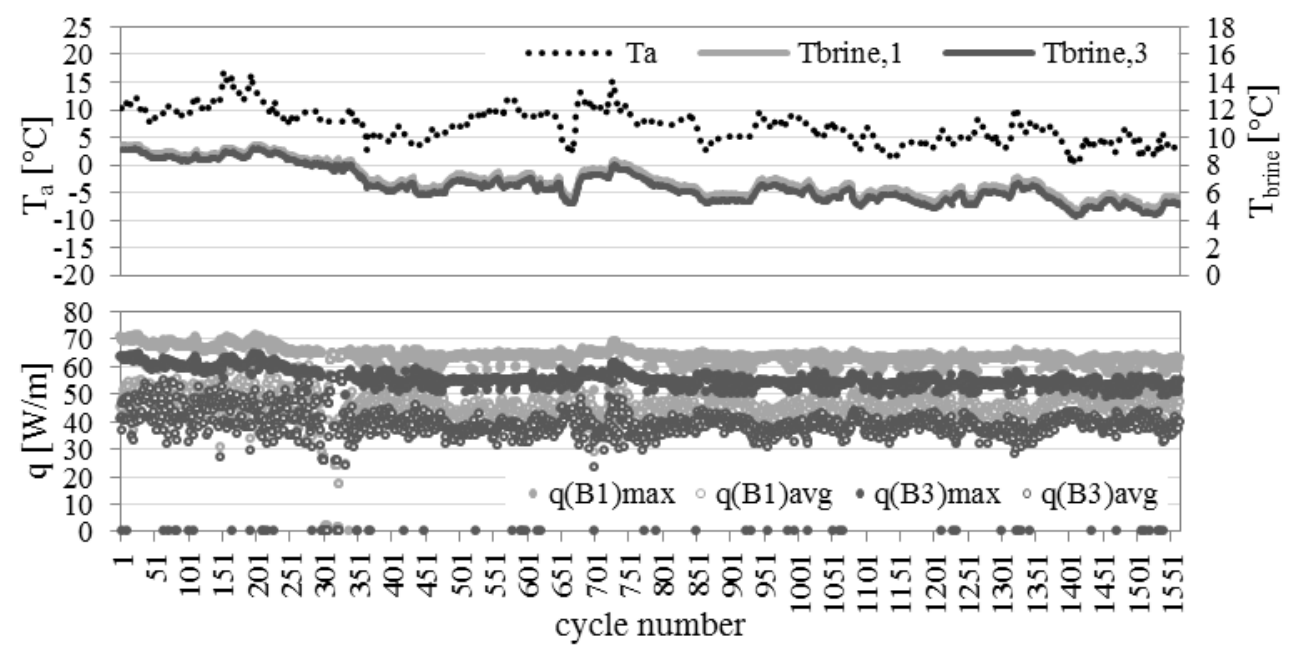

Fig. 2. The exploitation of the heat pump's energy source with three boreholes (one month of the operation in October and November 2017). 


\subsection{Operation with five boreholes in 2018}

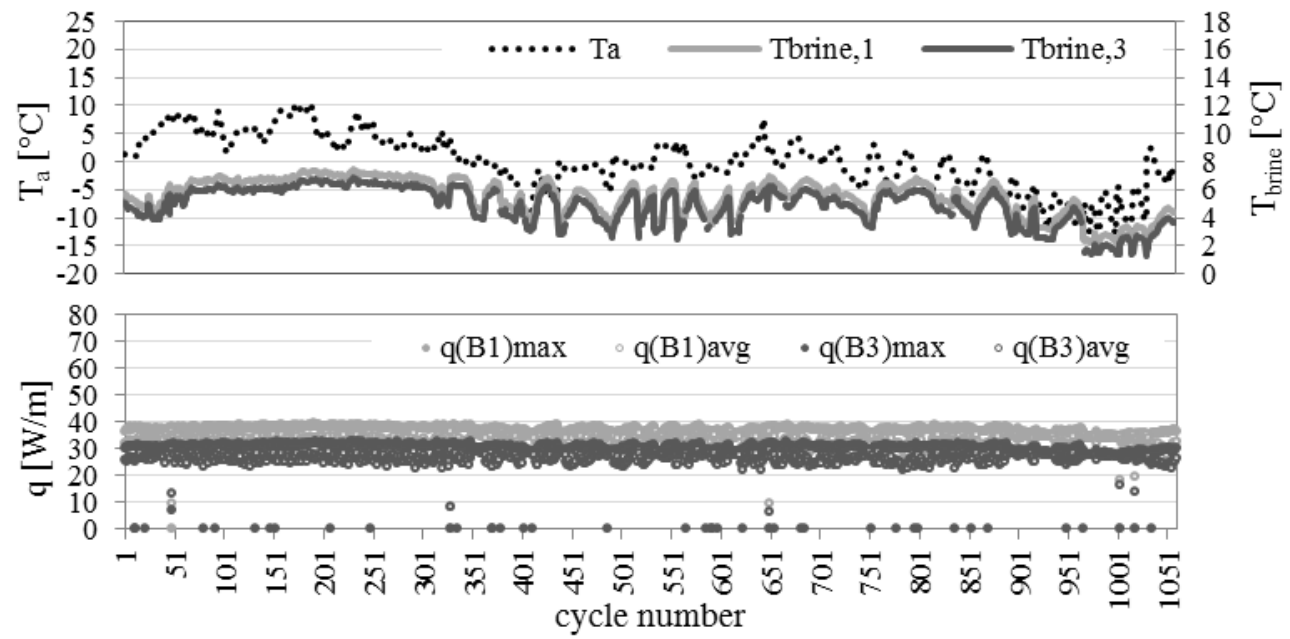

Fig. 3. The exploitation of the heat pump's energy source with five boreholes (six weeks of the operation from January to March 2018).

The performance of the low heat source of the brine-to-water heat pump (operation with five boreholes after working with three boreholes for over two and half months) is presented in the Figure 3. The ambient air temperature $\left(\mathrm{T}_{\mathrm{a}}\right)$ during six weeks presented in the Figure 3 (end of January, February and beginning of March) ranged between $-13^{\circ} \mathrm{C}$ and $+10^{\circ} \mathrm{C}$. The Borehole 1 maximum power specific extraction rate was around $\mathrm{q}_{(\mathrm{B} 1) \max }=38 \mathrm{~W} / \mathrm{m}$ and Borehole 3 - around $\mathrm{q}_{(\mathrm{B} 3)_{\max }}=31 \mathrm{~W} / \mathrm{m}$. The average power extraction rate for boreholes also differed one from another and were around 4-5 W/m higher for Borehole 1. When the ambient air temperature was low, the average power extraction rates of boreholes in the single cycles have been getting close to the maximum values. Still, despite the greater load of the Borehole 1, the brine temperature on its outlet $\left(\mathrm{T}_{\text {brine,1 }}\right)$ was higher than for the Borehole $3\left(\mathrm{~T}_{\text {brine,3). The flow temperature of the brine was }}\right.$ not stable in both boreholes. During examined period it changes by about $5.5 \mathrm{~K}$. In the Figure 3 it is visible that, when the ambient temperature is relatively high (around $5^{\circ} \mathrm{C}$ ), the brine temperature is stable, but it begins to fluctuate at lower ambient temperatures. This indicates that the exploitation of the heat pump with three boreholes overcooled the lower heat source.

\subsection{Analysis of the work cycles}

An important element of the analysis of experimental data is paying attention to individual heat pump cycles while working with five or three boreholes. The Figure 4 shows a single heat pump cycle in different operating periods, for similar ambient temperatures (around $0^{\circ} \mathrm{C}$ ) and for the same cycle duration. The left side of Figure 4 shows the work of the BHE 1 and BHE 3 in November 2017 (during the operation of three boreholes), and the right side stable operation of five boreholes in January 2015. Initial disturbances result from the construction of the installation. The initial high outlet temperature results from the measurement of the temperature of heat carrier fluid from the pipes localised in the technical room and in the shallow soil layers between the measurement well and the heat pump. In next minutes of the cycle, the parameters stabilize. In the case of working with 
five boreholes (right side), it can be seen that after reaching the power specific extraction rate of $40 \mathrm{~W} / \mathrm{m}$, the work stabilizes and the temperature drop in the whole cycle does not exceed $0.6 \mathrm{~K}$. Average difference in inlet and outlet temperature in the stable phase of the cycle is $5.2^{\circ} \mathrm{C}$. The average glycol temperature is $7.1^{\circ} \mathrm{C}$. In the case of operation with three boreholes, the initial disturbances are caused by the same reason, however, the system does not reach the stable state, striving to achieve the required power specific extraction rate. The temperature drop during the cycle exceeds $1.5 \mathrm{~K}$. The average difference in inlet and outlet temperature in the stable cycle phase is $4.9^{\circ} \mathrm{C}$. The average glycol temperature is $4.1^{\circ} \mathrm{C}$. These differences have a direct impact on the heat pump's coefficient of performance and hence on operating costs. It should also be noted that the experiment was carried out in the period of ambient temperatures not falling below $0{ }^{\circ} \mathrm{C}$ due to the high risk of freezing of the lower source. During operation with five BHE's, regardless of the ambient temperature, the operating parameters were very similar.

operation with three BHE's
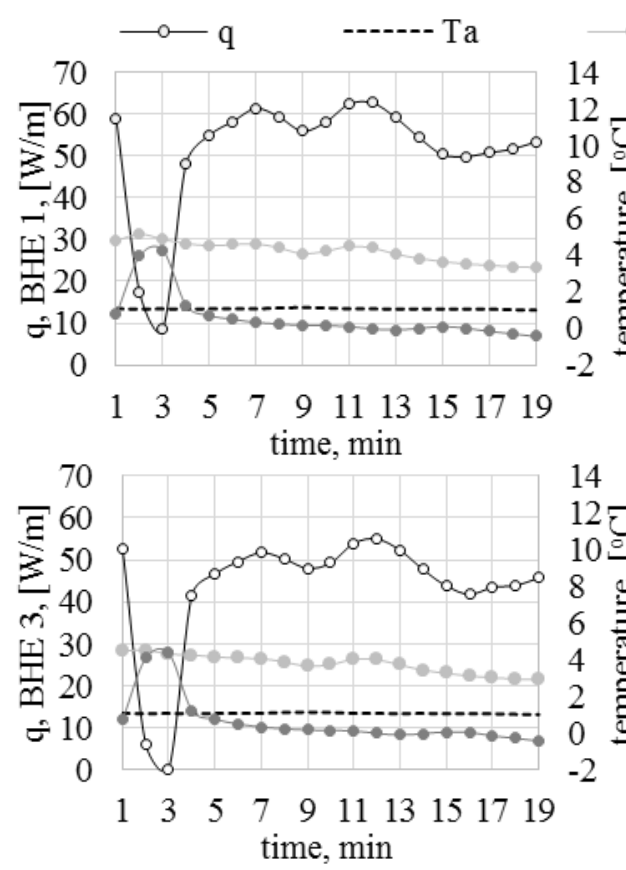

operation with five BHE's
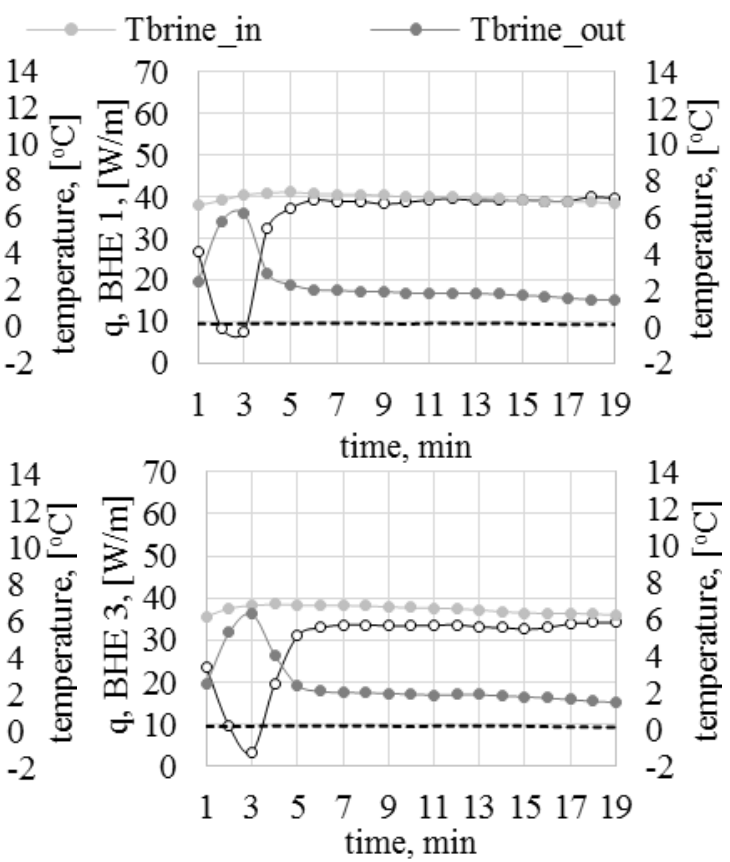

Fig. 4. The typical work cycles of the heat pump's lower heat source with three (left) and five (right) boreholes.

\subsection{Discussion}

The measurement outcomes summary of the heat pump's low heat source working with five and three boreholes are set together in Table 1. The outcomes concern the borehole number 1 (actively regenerated) and 3 (not actively regenerated). The summary applies to two months of stable operation in the beginning of 2015, operation with three boreholes in the beginning of heating season 2017/2018 and operation with five boreholes from December 2017 to April 2018. Average ambient temperatures are different in analysed months, but the data still can be compared. In 2015 the average specific power extraction rate is around $29 \mathrm{~W} / \mathrm{m}$ for Borehole 1 and $24 \mathrm{~W} / \mathrm{m}$ for Borehole 3. When the heat pump works with three 
boreholes the specific power extraction rate rise significantly, but its value changes with the change of the heat load depending on the ambient temperature (Table 1and Figure 6). After returning to work with five boreholes, the power extraction rate drops to $32 \mathrm{~W} / \mathrm{m}$ (BHE 1) and $26 \mathrm{~W} / \mathrm{m}$ (BHE 3) and its level no longer depends on the heating demand. Still, the outlet brine temperature is much lower in months with higher heat loads (lower ambient temperatures, compare Jan-15 and Jan-18).

Table 1. The summary of the system with three and five boreholes performance data.

\begin{tabular}{|c|c|c|c|c|c|c|c|c|}
\hline \multirow{3}{*}{ type of exploitation } & \multirow{3}{*}{ date } & \multicolumn{3}{|c|}{ Borehole 1} & \multicolumn{3}{|c|}{ Borehole 3} & \multirow{3}{*}{$\begin{array}{l}\mathrm{T}_{\mathrm{a}} \\
{ }^{\circ} \mathrm{C}\end{array}$} \\
\hline & & $\mathrm{q}_{\max }$ & qcycle & $\mathrm{T}_{\mathrm{B}, \mathrm{avg}}$ & $\mathrm{q}_{\max }$ & qcycle & $\mathrm{T}_{\mathrm{B}, \mathrm{avg}}$ & \\
\hline & & $\mathrm{W} / \mathrm{m}$ & $\mathrm{W} / \mathrm{m}$ & ${ }^{\circ} \mathrm{C}$ & $\mathrm{W} / \mathrm{m}$ & $\mathrm{W} / \mathrm{m}$ & ${ }^{\circ} \mathrm{C}$ & \\
\hline \multirow{2}{*}{ five boreholes } & Jan-15 & 38.7 & 29.0 & 7.7 & 33.3 & 24.1 & 7.1 & 3.6 \\
\hline & Feb-15 & 39.1 & 29.4 & 7.4 & 33.4 & 24.2 & 6.9 & 1.6 \\
\hline \multirow{2}{*}{ three boreholes } & Oct-17 & 66.6 & 47.8 & 8.8 & 59.6 & 41.9 & 8.5 & 11.1 \\
\hline & Nov-17 & 62.7 & 45.7 & 6.1 & 54.1 & 38.6 & 5.7 & 6.2 \\
\hline \multirow{5}{*}{ five boreholes } & Dec-17 & 36.4 & 31.5 & 5.5 & 30.3 & 25.6 & 4.9 & 3.8 \\
\hline & Jan-18 & 37.1 & 32.4 & 5.9 & 30.4 & 26.2 & 5.3 & 3.6 \\
\hline & Feb-18 & 37.1 & 32.7 & 5.5 & 30.5 & 26.5 & 4.8 & -1.3 \\
\hline & Mar-18 & 36.6 & 32.4 & 4.9 & 30.1 & 26.1 & 4.2 & 0.9 \\
\hline & Apr-18 & 37.6 & 32.2 & 7.2 & 31.6 & 26.6 & 6.6 & 10.0 \\
\hline
\end{tabular}

The brine temperature during stable operation is high and invariable (Figure 1 and Table 1), which is also shown in the previous article [7]. After starting work with three boreholes, despite high external temperatures (above $0^{\circ} \mathrm{C}$ ), this temperature drops significantly, and the slope of the trend line for 2 months of such work is higher than at the 2-week test in January 2017 [7]. It is also visible that after returning to work with five boreholes, the brine temperature does not return to previous balance and at ambient temperatures of around $10^{\circ} \mathrm{C}$ it drops even to $1^{\circ} \mathrm{C}$.
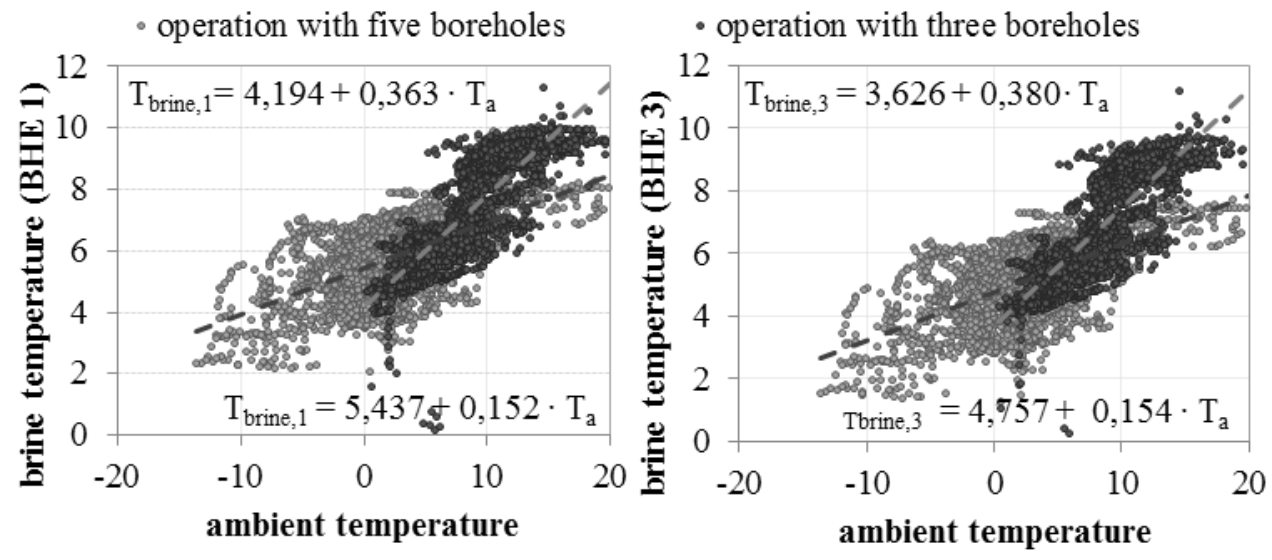

Fig. 5. The relation between the ambient air temperature and brine temperature in heat pump system.

Figure 6 shows the relation between ambient temperature and power specific extraction rate. In the case of operation with five boreholes, the power specific extraction rate is constant, regardless of the outside temperature and equals to $35-40 \mathrm{~W} / \mathrm{m}$. In the case of operation with three boreholes, the power specific extraction rate varies and depends on the heat load related to the ambient temperature. It should also be noted that the non-regenerated borehole reaches a lower power extraction rate and is more sensitive to the load increasing (as seen by the slope of the trend line). The system designed and operated in 
this way, as might be expect, in the period of low ambient temperatures would achieve insufficient power extraction, thereby significantly increasing the cost of the system operating. The system efficiency would also decrease in subsequent years of operation due to a significant drop in soil temperature and lack of regeneration (BHE 3).
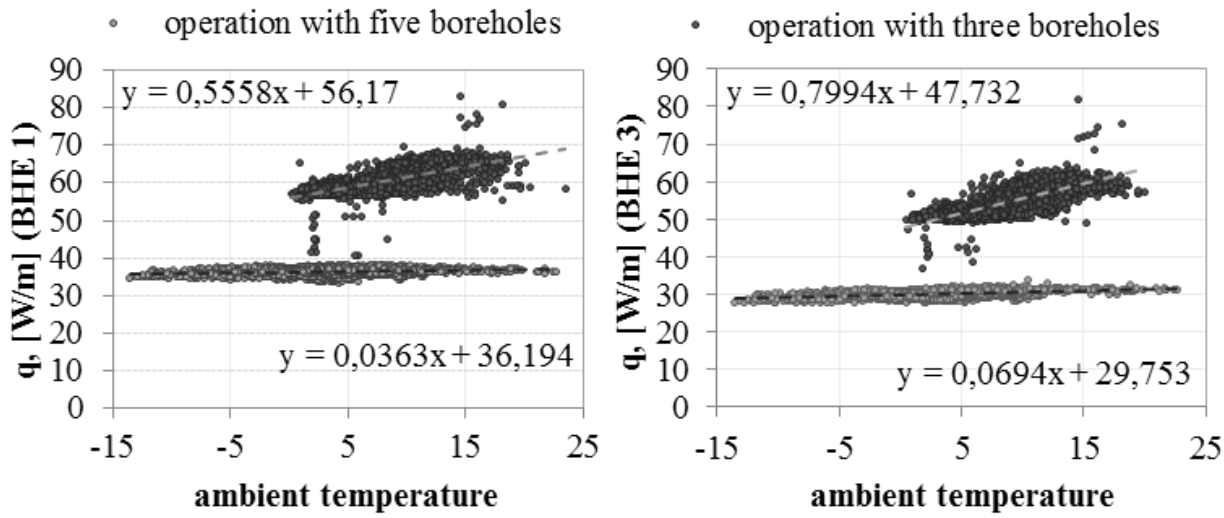

Fig. 6. The relation between the ambient air temperature and power specific extraction rate.

\section{Conclusion}

The analysis of the power extraction rate change in time and under various loads demonstrated some consequences of the Ground Source Heat Pump lower heat source overload. Present research confirmed that the exploitation in overload conditions cause drop in brine temperature. This phenomenon occurs in low ambient temperatures [7] but also when the building heat load is small. The heat extraction rate in overloaded BHE (exploitation with three boreholes) indicates the relationship with the building load, which did not occurred while working in stable conditions. This is caused by the ground temperature drop around the BHE during the operation with three boreholes. Moreover, the heat extraction rate value does not stabilize on certain level during heat pump work cycle. Even not very long term exploitation in overload conditions (about two and half months) made source unstable. After the return to the exploitation with five boreholes, the power extraction rate came back to previous state, but the brine temperature stayed low and unstable till the end of heating season. It has been fluctuating which the changes of heat load, which was not the case of stable performance.

\section{References}

1. B. Nordell, A. K. Ahlstrom, NATO Science Series, 193-203 (2005)

2. A. Casasso, R. Stehi, Renew. Energ. 62, 737-746 (2014)

3. J. D. Spitler, S. E. A. Gehlin, Renew. Sust. Energ. Rev. 50, 1125-1137 (2015)

4. A. Liuzzo-Scorpo, B. Nordell, S. Gehlin, Geothermics 56, 119-127 (2015)

5. L. Lamarche, S. Kajl, B. Beauchamp, Geothermics 39, 187-200 (2010)

6. F. Piscaglia, A. Blasi, S. Del Moro, F. Polonara, A. Arteconi, L. Zanarelli, A. Renzulli, Geothermics 62, 61-69 (2016)

7. N. Fidorów-Kaprawy, E. Stefanowicz, W. Mazurek, M. Szulgowska-Zgrzywa, A. Bryszewska-Mazurek, E3S Web of Conf. 22, 00045 (2017) 